\title{
The Case against Semantic Relativism
}

Teresa Marques

\section{ABSTRACT}

This paper presents reasons against semantic relativism. Semantic relativism is motivated by intuitions that are presumed to raise problems for traditional or contextualist semantics in contested domains of discourse. Intuition-based arguments are those based on competent speakers' putative intuitions about seeming faultless disagreement, eavesdropper, and retraction cases. I will organize the discussion in three parts. First, I shall provide a brief introduction to the intuition-based arguments offered in favor of semantic relativism. Second, I shall indicate that there are ways for contextualism to explain the (appearance of) intuitions that support semantic relativism. Third, I shall review some experimental results and independent arguments that put into question the appeal of semantic relativism.

\section{Intuition-based Arguments}

Intuitions about retraction and disagreement play a crucial role in arguments for semantic relativism about epistemic modals, deontic modals, conditionals, knowledge attributions, or value and personal taste claims: the use of these expressions seems to be dependent on people's perspectives, either on a relevant body of information available, or a relevant standard of taste. But while absolutists seem unable to capture the perspective-dependence of claims in that range, indexical-contextualists seem unable to account for the presumed intuitions of competent speakers involving disagreement and retraction cases. Disagreements between people with different perspectives in these areas seem to occur, as do retractions of past claims made by subjects after a change of perspective (where the perspective-independent facts remain the same). Likewise, we are owed a suitable explanation of what is going on with eavesdropper cases. 
The papers by Dan Zeman, Filippo Ferrari, and Andy Egan and Dirk Kindermann in this volume provide good introductions to different aspects of the contemporary debate on relativism, and I will refer to them since they offer a good background to the discussion in this paper.

Here is an example from Egan and Kindermann (in this volume) which illustrates the prima facie problem eavesdropper cases create to contextualist semantics.

TASTE: $F$ and $G$, who are from Australia, are having breakfast. $G$ says to $F$, "mm, vegemite toast is delicious". F replies, "that's true! Such a joy of a morning". At the next table, $\mathrm{H}$ and J, who are from the United States, overhear. J has never tried vegemite, but knows that $\mathrm{H}$ has. J turns to $\mathrm{H}$, hand poised to lift a piece of vegemite toast to her mouth, and asks, "is that true?" H replies, "no, it's not. Vegemite toast tastes like feet."

Cases like this are supposedly problematic for contextualists. If what $\mathrm{G}$ says is "vegemite toast is delicious, from my perspective," $\mathrm{H}$ 's denial is, at best, misguided. But $\mathrm{H}$ seems to be perfectly within his rights to reply as he does. Absolutists do not have problems with eavesdropper cases, since whatever the sentence "vegemite is tasty" says, it is absolutely true (or, in our view, false!). Other kinds of examples are discussed in eavesdropper cases, for instance epistemic modals. Typically, these examples involve people with disparate opinions of what might or should be the case given the information available to them when they make their judgments.

Intuitions about seeming faultless-disagreement cases also pose a problem for both absolutists and contextualists. Faultless disagreement can be characterized as follows:

A faultless disagreement is a situation where there is a thinker $A, a$ thinker $B$, and a proposition (content of judgment) $p$, such that:

(a) A believes (judges) that $p$ and $B$ believes (judges) that not- $p$

(b) Neither A nor B has made a mistake (is at fault). (Kölbel 2004, 53-

54) 
Consider, as an illustration, this case offered by Egan and Kindermann (also this volume):

TASTE*: $F$ and $G$, who are from Australia, are having breakfast. $G$ says to $F$, "mm, vegemite toast is delicious". At the next table, $\mathrm{H}$ and $\mathrm{J}$, who are from the United States, are sitting down to their own breakfast. J turns over to F and G's table, spitting out a bite of Vegemite, and says to them, "Vegemite toast is not delicious! This stuff tastes like feet."

A flat-footed reaction to have about this case: When G says "Vegemite toast is delicious" and J says "Vegemite toast is not delicious", they are disagreeing. (And they are disagreeing about whether Vegemite toast is delicious.) But nobody need be making a mistake: Both are (or on suitable fillings-in of the case, both could easily be) getting it right, "from their own perspective." (Egan and Kindermann, this volume)

Absolutists are supposed to have trouble explaining that nobody need be making a mistake, although they have no problem explaining the existence of disagreement. The absolutist's prediction is that "vegemite toast is delicious" is either true or false (absolutely). Hence, one of $\mathrm{G}$ or $\mathrm{F}$ in this scenario must be making a mistake. Contextualists are supposed to have trouble explaining this scenario, because although they can explain why none of the speakers is making a mistake, they apparently can't explain what the interlocutors disagree about, since $G$ is saying something like "Vegemite toast is delicious, from my perspective" and $\mathrm{J}$ is saying "Vegemite toast is not delicious, from my perspective," which can both be true and accepted as such.

Finally, intuitions about the retraction of claims in disputed domains are meant to further undermine the plausibility of contextualist or absolutist semantics for the contested terms in those domains. Consider this case from MacFarlane (2011):

Sally and George are talking about whether Joe is in Boston. Sally carefully considers all the information she has available and concludes that there is no 
way to know for sure. Sally says: "Joe might be in Boston." Just then, George gets an email from Joe. The email says that Joe is in Berkeley. So George says: "No, he isn't in Boston. He is in Berkeley."

In this scenario, MacFarlane claims, it would be natural for Sally to retract her assertion that Joe might be in Boston, saying something like "I guess I was wrong; I take that back", and it would not be normal for her to say, "Fine, he can't be in Boston, but I still stand by what I said." The scenario assumes that intuitions about what it is more natural is something the contextualist would have trouble explaining since the speaker would be taking back a correct assertion of a true proposition.

Relativist semantic approaches are meant to be better equipped to handle these cases. But there are different versions of semantic relativism, making different kinds of commitments and theoretical requirements. Ferrari (this volume) mentions a distinction between two ways of understanding semantic relativism related to the one made by Gareth Evans (1985): the "non-indexical contextualism" defended by Kölbel $(2003,2004)$, 'NIC' henceforth, and the "assessment relativism" advocated by MacFarlane and others, 'AR'.

NIC is primarily a view about propositions. Traditionally, propositions are possibleworld-neutral: the same proposition expressed in an actual utterance might be expressed when thought of as made under counterfactual circumstances, "in" a different world. Propositional truth is hence relative to a world, in that we need a world to evaluate the truth of a proposition. Philosophers like David Lewis (1979), have argued that we also need time-neutral and subject-neutral propositions for different reasons to account for de se phenomena. The truth of such propositions must thus be further relativized to times or subjects. Truth-relativists of this stripe try to address the philosophical issues they confront in the previous cases described by arguing for additional relativization of propositional truth, to judges or taste standards. However, truth as a norm for assertoric acts remains absolute on NIC, because the needed parameters are provided once and for all by the context that the act concerns. 
To illustrate consider that in the intuitive retraction case above, the apparent natural response "I take that back" would suggest that an alternative to the standard contextualist view should be correct. For example, one alternative to the canonical Kratzerian contextualist analysis of modals ${ }^{1}$ is that the quantification over a domain of possible worlds compatible with the information available at the context of use is not part of the content. Such an alternative view could take the shape of Egan (2007)'s proposal that bare epistemic modals express centered world propositions whose truth varies with respect to different centers in the same world:

It might be the case that $P$ is true relative to a centered world $(w, t, i)$ iff it's compatible with everything that's within i's epistemic reach at $t$ in $w$ that $P$. (Egan 2007, 8)

This view yields some predictions about the falsity of bare epistemic possibility modals (BEPs) made in the past - if the prejacent of the modal (e.g., "Joe is in Boston") is false with respect to the information available to a present hearer, then the modal is false. The view makes no strong requirement about the retrospective assessment of the correctness of that claim. It would be consistent with the view to say that it is natural for the speaker to assert "it might be the case that $p$ " when $p$ is compatible with the information available to her at the time of utterance, and for the speaker to take back

${ }^{1}$ On standard Kratzerian accounts, the relevant epistemic situation is the state of information that is available in the context where the speaker uses an epistemic modal sentence like "Joe might be in Boston". An alternative sentence, "From what I know, Joe might be in Boston", makes it explicit that the modal base (set of worlds selected by the context that are meant to be compatible with Joe being in Boston) are the worlds consistent with the information available to Sally. The sentence in the example is a bare epistemic modal and gives no explicit indication of how the modal base is to be restricted. Its modal base is nonetheless also determined in context: the context of use determines a set of possible worlds compatible with the relevant information available at the context of use. 
the assertion when $p$ is no longer compatible with information available to her at a later time.

There is however a stronger normative view about the retraction of epistemic possibility modals. The alternative view is not that it would be natural for Sally to retract, but that she ought to.

Intuitions about retraction may be used against non-indexical contextualism. Upon learning that Joe is down the hall, Sally ought to retract her assertion that Joe might be in Boston. Non-indexical contextualists lack the resources to explain this fact, since their account of the norm of assertion appeals only to the notion of truth relative to the context of assertion (a feature Sally's assertion has). (MacFarlane, 2014, 256)

This challenges any view according to which an assertion is correct only if it is true relative to the context of assertion. But this relies essentially on the strength of the intuition that a retraction is obligatory when the newly available information entails the falsity of the prejacent of the modal.

MacFarlane seems to be relying on a point Michael Dummett (1978) made in connecting the truth of what we say and the point of our saying it, i.e., the point of assertion. Dummett's claim was that a "well-defined consequence of an assertion's proving incorrect" is that the speaker must withdraw it" (Dummett 1978, 20). Thus, by holding that retraction is mandatory in what he calls the assessment context, MacFarlane is AR plausible. If it were the case that a retraction of a previous assertion is required, then that assertion must be incorrect. But if the assertion was correct (as MacFarlane puts it, "accurate") when it was made (the speaker said what was true when she spoke), and is incorrect ("inaccurate") when its retraction is required, then its correctness conditions must be themselves relative. This would be the point of assessment-relative truth: to capture this feature of some assertions whose correctness would itself be assessment-relative. This is the more radical relativist view on which it is the appraisal of a "use" of a proposition (as MacFarlane puts it) that may 
change: while an assertion of "vegemite is tasty" or of "Joe might be in Boston" might meet a truth norm when evaluated relative to the standard prevailing in the context in which it is made, thus being perfectly accurate, it may come to be false, and hence wrong, when evaluated from another context. ${ }^{2}$ Evans (1985) argues that this is importantly different from NIC and more difficult to motivate, and we agree with him (cf. Marques 2014a, 2018), as we argue below.

\section{Contextualist Replies}

There are several responses to the intuition-based arguments offered to motivate truthrelativism. ${ }^{3}$ Since the point of this paper is to argue against semantic relativism, I shall be brief in considering those replies. Zeman's contribution to this volume offers a nice compilation of the variety of responses that contextualists have offered with respect to faultless-disagreement cases. He identifies three kinds of strategies. First, there are authors that argue that the examples based on the appearance of faultless disagreement are often undetermined. The descriptions of the putative intuitive cases are said to fail to distinguish between "exocentric" and "autocentric" uses of the relevant phrases, to ignore the possibility of collective uses, or of generic uses. Once those distinctions are made available, the intuitions about the existence of disagreement should dissipate (cf. Schaffer 2011, Glanzberg 2007, Stojanovic 2007, Cappelen and Hawthorne 2007).

\footnotetext{
${ }^{2}$ Wright (2016: 189) also points out the significance of the distinction between NIC and AR. In contrast, Cappelen and Hawthorne (2009) and Cappelen and Huvenes (2018) adopt the sort of view I'm opposing here, contending that the most salient difference among different relativist views "is arguably that relativists have different views about what propositions are true or false relative to"; cf. Kölbel (2015). This take informs choices in the presentation and discussion of the issues, with confounding consequences.

${ }^{3}$ Kölbel $(2009, \S 3)$ lists additional related data.
} 
Second, some disagreements and impressions of disagreement are said to be pragmatic. For instance, some impressions of disagreement can result from a presupposition that interlocutors are speaking from the same perspective (presupposition of commonality) and may dissipate once they realize that is not the case; or they may result from presupposing that at least one of the interlocutors are right, or that one of them is speaking from a superior perspective. Alternatively, other disagreements should rather be recognized as metalinguistic. Finally, some disagreements may concern incompatible conversational moves (cf. López de Sa 2008, Parsons 2013, Zakkou 2015, Sundell 2011, Plunkett and Sundell 2013, Ludlow 2014, Silk 2016). These pragmatic disagreements, or impressions of disagreement, are compatible with contextualism. Third, disagreements that are pragmatic in nature are sometimes claimed to be motivated by conative or non-doxastic disagreements, where those who disagree in attitude may have conflicting attitudes ${ }^{4}$ (cf. Huvenes 2012, Marques 2015, 2016a, 2016b, 2019)5.

Presumably some of these strategies are available concerning responses to the intuitive strength of eavesdropper cases. Although most explanations of the intuitions of disagreement focus on evaluative or taste predicates, some focus specifically on epistemic and deontic modal cases. For instance, Dowell $(2011,2013)$ persuasively argues that disagreement and eavesdropper cases are not real challenges to the standard Kratzerian contextualist semantics for modals. She suggests that when the proper constraints on contexts are satisfied, namely, when speaker's domain restricting intentions are properly made manifest (a condition she names "Publicity") the intuitions about the challenging cases - disagreement, eavesdroppers - dissipate.

Finally, several people have questioned the strength of the retraction of intuitions, which I will discuss below.

\footnotetext{
${ }^{4}$ The notion of conflicting attitudes was already advanced by Stevenson (1944).

${ }^{5}$ Absolutists can also offer replies to faultless disagreement cases, as Zeman (this volume) explains. (Cf. Shafer 2011).
} 


\section{Limitations of Relativism}

Many authors have pointed out that relativists are not better positioned to explain disagreement data than contextualists are. ${ }^{6}$ NIC aims to account for relativism by ascribing exclusionary contents to utterance contents such that "it has to be the case that at least one of them is false" (Knobe and Khoo 2016, 1), or, in other words, such that they can't be both right. Like others, we have argued that exclusionary contents are neither necessary nor sufficient for disagreement. First, they don't suffice to explain disagreement: If Lewis and his followers are right, an utterance of "I am making a mess" and one of "I am not making a mess" by another agent have exclusionary contents, but we don't have impressions of disagreement about them.

Dinges (2017a, 730; 2017b, 501) buys the exclusionary-content explanation, and, in work purporting to establish that we should adopt relativism on the abductive grounds that it is more "elegant" than rival views $(2017 \mathrm{~b}, 497)$, he confronts this argument. He submits (2017b, 502) that there are no assertions (or there shouldn't be?) of de se contents. ${ }^{7}$ However, proponents of de se contents have provided well-developed

\footnotetext{
${ }^{6}$ As is argued by Stojanovic (2007), Moruzzi (2008), Rosenkranz (2008), lacona (2008), Francén (2010), etc.

${ }^{7}$ Caso (2014) also confronts the objection, like Dinges from a perspective that is consistent with NIC even if his sympathies lie with AR. He buys the explanatory exclusion explanation of disagreement too $(2014,1322)$. He dismisses the objection by claiming that the relativist view is not intended to be applied to the discourses for which de se or de nunc contents have been advanced $(2014,1314,1317)$. This overlooks the point of the objection, that is, that the possibility of such discourses shows that the relativist alleged explanans for the impression of disagreement is no good, because it might be in place without any impression of disagreement being triggered.
} 
proposals to account for their felicitous assertion even in such cases. ${ }^{8}$ And I have argued elsewhere (cf. Marques and García-Carpintero 2014, Marques 2014a), there are felicitous assertions of what on relativist accounts are contents that are neutral with respect to standard-of-taste parameters (contradicting Dinges' claim). Two foodies with fully developed taste sensitivities, fully aware that there are serious differences in their respective rulings, might engage in the debates we are considering, "this is tasty" - "no, it isn't", and it might be perfectly rational for them to do so. ${ }^{9}$

Exclusionary contents are not necessary for disagreement, either. In previous work, I mentioned Horn's cases of "metalinguistic negation"10 (Marques 2014b, 2015), in connection with Barker's $(2002,2013)$ observation that one can use expressions with an indeterminate meaning to make proposals for their contextual precisification. Given this, one might use the negations to reject such a proposal. Sundell (2011) persuasively elaborates on related ideas, and there is now a huge literature developing the point ${ }^{11}$.

Khoo and Knobe (2016) confirm previous experimental evidence that ordinary speakers might be sensitive to the point that there might be disagreements without exclusionary contents ${ }^{12}$. As already mentioned in the previous section, it has also been

\footnotetext{
${ }^{8}$ For recent versions, see the papers by Recanati, Maier, Weber and Kindermann in García-Carpintero and Torre (2016).

${ }^{9}$ Dinges (2017a: 735) considers cases of this sort.

${ }^{10}$ These are cases in which one uses expressions of disagreement to object to the appropriateness of an assertion on grounds other than the falsity of its content: "John failed some students" - "No, he failed all of them"; "John has a car" - "No, he has a Ferrari Testarossa". These fall under the various forms of pragmatic disagreement mentioned earlier (Cf. also García-Carpintero 2008).

${ }^{11}$ Cf. for instance Plunkett and Sundell (2013), Ludlow (2014), López de Sa (2015). 12 Sarkissian et al. (2011) present evidence that also appears to suggest that previous results about presumed folk intuitions can be accounted for by the fact that relevant disparities in the judges were not made salient. (See Marques and García-Carpintero (2014: 707-8) for some reservations about the interpretation of such results.)
} 
repeatedly pointed out, and developed at length in different directions, that rejections might tap into disagreements of a practical nature, without the need for exclusionary content. ${ }^{13}$ The purported explanation of the disagreement data that NIC offers doesn't thus appear promising.

A similar diagnosis applies to AR. Here the issue turns primarily on whether there is any good reason to accept that, as MacFarlane contends, the same assertion can be accurately made in its context, but assessed as inaccurate or incorrect from another context providing a conflicting appraisal. With respect to disagreements, specifically, MacFarlane agrees that under one understanding of disagreement, relativists are not better positioned than contextualists. In fact, we should ask, why would people disagree when they don't share a perspective? MacFarlane's 2007 response is one that any contextualist can likewise offer:

Perhaps the point is to bring about agreement by leading our interlocutors into relevantly different contexts of assessment. If you say "skiing is fun" and I contradict you, it is not because I think that the proposition you asserted is false as assessed by you in your current situation, with the affective attitudes you now have, but because I hope to change these attitudes. Perhaps, then, the point of using controversy inducing assessment-sensitive vocabulary is to foster coordination of contexts. We have an interest in sharing standards of taste, senses of humor, and epistemic states with those around us. The reasons are different in each case. In the case of humor, we want people to appreciate our jokes, and we want them to tell jokes we appreciate. In the case of epistemic states, it is manifestly in our interest to share a picture of the world, and to learn from others when they know things that we do not. (MacFarlane 2007: 30). (My emphasis)

\footnotetext{
${ }^{13}$ Marques and García-Carpintero (2014) and Marques $(2015,2016,2019)$ appeal to a "hybrid expressivist" view.
} 
Considerations about the pull towards coordination can be met without embracing relativist semantic revisions. To see this, consider a case that Dinges $(2017 b, 503)$ uses for an abductive argument for relativism in which A, whom B barely knows, offers advice to her regarding a restaurant by uttering "The food is tasty". As Dinges points out, if $C$ then asks $B$ about the food at the restaurant, it would be inappropriate for $B$ to produce in her turn "The food is tasty" without having yet tried it. If, however, the topic had been all along the restaurant opening hours or food specialty, it would have been perfectly ok for B to pass on A's testimony. Dinges $(2017 \mathrm{~b}, 511)$ contends that the relativist has a simple explanation, which I rather doubt, but I lack the space to go into this here.

Be this as it may, Dinges' discussion highlights the difficulties that relativism poses to make sense of exchanges like that between $A$ and $B$, and the very existence of a testimonial practice understood along the lines it promotes. We must put aside situations in which $A$ and $B$ are justified to take $A$ 's claim to concern a common standard; for in such cases, disagreement offers no support for relativism: at least one party makes a false claim, and whatever good standing both parties have can only be epistemic. But, if so, A's claim must be equivalent to "I like the food there" (2017b, 514). Given that a commonality assumption is not in place, that doesn't help B to make her own mind, and should discourage her adoption of the relativist proffered proposition as good enough for her own circumstances. Moreover, as can be appreciated from the possibility of pragmatic and conative conflicts, contextualists can appeal to conflicts over incompatible attitudes consistent with conversations like the described being attempts to change other people's attitudes.

MacFarlane later adopted a different approach. Instead of trying to explain the point of communicating and disagreeing over perspectival contents, he now argued for pluralism about disagreement and faultlessness:

Instead of arguing about what is "real" disagreement, then, our strategy will be to identify several varieties of disagreement. We can then ask, about each dialogue of interest, which of these kinds of 
disagreement can be found in it, and we can adjudicate between candidate theories of meaning by asking which theories predict the kinds of disagreement we find. (MacFarlane 2014: 119)

Zeman (this volume) nicely introduces the varieties MacFarlane considers. ${ }^{14}$ I will not go over these here. Yet, once the discrimination between different kinds of putative disagreements has been done, it is no longer clear whether speakers may plausibly be expected to have intuitions about each of those senses of disagreement. ${ }^{15}$ Some of the more "minimal" forms MacFarlane declares to be types of disagreement (such as simple noncotenability, i.e. exclusionary contents) can of course be stipulated to be a form of disagreement, but it's unclear what independent motivation can be offered in its support.

Egan (2007) and MacFarlane (2011), among others, also argued that contextualist semantics cannot account for eavesdropper cases. But, with respect to deontic and epistemic modals, not only do contextualists have a response, as Dowell $(2011,2013)$ claims; competent speakers don't appear to share the intuitions that would support revisionary relativist theories. In a joint paper, Knobe and Yalcin (2014) experimentally tested eavesdropping and retraction in cases involving epistemic modals. With respect to extra-contextual assessors their experiments revealed that eavesdroppers did not tend to judge that a claim like Sally's 'Joe might be in Boston' would be false when new information about Joe's whereabouts came to light, against the presumed intuitions that eavesdroppers would predominantly assess the sentence as true only if 'Joe is in Boston' were consistent with the information available to them (qua assessors).

And finally, the most serious intuition-based argument against contextualism concerns retraction cases. It's the presumed requirement to retract that makes AR distinctive, and without it AR would be unmotivated. As I have argued (Marques 2014, 2018), it's

${ }^{14}$ Others argue for a unified notion of disagreement, e.g. Belleri and Palmira (2013).

${ }^{15}$ For additional skepticism about some of the notions involved here, see for instance Palmira (2015), Carter (2014), Eriksonn and Tiozzo (2016) 
not just that the requirement to retract doesn't seem well motivated. As experimental data suggests, speakers tend to disagree that what Sally said ("Joe might be in Boston") is false, while tending to agree that it would be appropriate for her to retract (Knobe and Yalcin 2014). This seems puzzling. However, this experiment didn't address the presumed requirement to retract that, as MacFarlane holds, motivates AR. In new experimental work, I found that indeed participants tend to disagree that the modal is false, and also tend to disagree that there is any requirement to retract when the truth of the prejacent of the 'might' claim is incompatible with new information available to them (Marques, manuscript).

There is a more serious reason against relativism. In a 1985-paper, Gareth Evans raised a challenge to the coherence of relative truth. A modification of the challenge can be given against AR. The main point is that rational sincere speakers cannot be bound by assessment-relative standards of correctness or accuracy, and that's why they are not required to retract assertions that were correctly made (true with respect to the intended context) with propositions as contents that turn out to be not true with respect to a new "assessment context".

Evans's point has an a priori character. It doesn't question the rationality of particular moves in an assertoric practice legitimized by assessment relativism, but rather the rationality of such a practice itself. The question is whether it's rational to implement a relativistic assertoric practice. MacFarlane (2014: 311-9) discusses the issue, but his rationale for justifying a practice modeled by AR only takes into consideration what I think is a negligible dimension. He offers considerations of economy: against what both NIC and contextualism mandate, it makes for some sort of efficiency not to have to keep track of the contexts relative to which claims or proposals are made, appraising them only with respect to current standards. I think that this lacks significance when weighed against the crucial reasons to have a practice of making assertions, asking questions or giving directions, such as pooling our information.

Cases like the following, which illustrate Evans's point, cast doubts on the requirement to retract past taste assertions: 
Imagine that Smith is aware that [...] her culinary opinions depend on her current dispositions towards food, etc. She knows, moreover, that certain standards are bound to change with time [...] that people in her family, when they reach 60 , lose the capacity to appreciate sweets. [In the future] she will not think that crème brûlée is tasty [...] On MacFarlane's account, she should be puzzled, in envisaging now that there will come to be situations in which she will be forced to retract her current assertion, while, from the viewpoint of her present context of assessment, those situations do not constitute at all a reason for so doing. [...] Certainly, Smith could have aimed at the context she knows she will occupy when she is 60-but had she done so, her standard of taste at 60 would still have been a standard of taste fixed by the context of utterance. (Marques 2014a: 370)

Similar seeming puzzles arise if we suppose that assertors of epistemic possibility modal claims are obliged to retract their present assertions when, in the future, the prejacents of the sentences they use turn out to be incompatible with the evidence they then acquire. Von Fintel and Gillies (2008) point out that not all 'might' claims are retracted in the face of new evidence (p. $81 \mathrm{ff})$. In fact, in the situation Sally finds herself in, it would have been perfectly natural for her to reply: "Look, I didn't say Joe is in Boston; I said he might be. Maybe he changed his mind and canceled the trip. Sheesh!"

When we make sincere assertions, we aim to speak truly, like Smith who asserts "Crème Brûlée is tasty" fully aware that she will find herself in situations where she will assert the negation of that sentence, or Sally who asserts "Joe might be in Boston" fully aware that there are probable situations in the near future in which she will assert "Joe can't be in Boston". If truth is assessment-sensitive, there is no final answer to the question of whether these assertions were correct when they were made. Speakers committed to the truth of what they asserted, and when they find themselves in situations where they assert the negation of the earlier claims, they commit to the truth of the new assertion. But they won't be in a position to uphold the 
correctness of the earlier assertion and of that of the later one. How could they purport to commit to both ? $^{16}$ There's no answer as to whether the aim of speaking truly is ever achieved. At best, speakers can aim to speak truly from a context. But, from which context? If we can give an answer to this question, then we also generate, as Evans put it, a "once-and-for-all assessment of utterances, according to whether or not they meet whatever condition the answer gave."

\section{REFERENCES}

Barker, C. (2002), "The Dynamic of Vagueness," Linguistics and Philosophy 25 (1): 1-36.

--- (2013), “Negotiating Taste," Inquiry 56(2-3): 240-257.

Belleri, D. and M. Palmira (2013), "Towards a Unified Notion of Disagreement," Grazer Philosophische Studien 88 (1):139-159.

Cappelen, H. and J. Hawthorne (2009), Relativism and Monadic Truth, Oxford: OUP.

--- and T. Huvenes (2018), "Relative Truth", in M. Glanzberg (ed.), The Oxford Handbook of Truth, Oxford: OUP, 517-542.

Carter, J. A. (2014), “Disagreement, Relativism and Doxastic Revision,” Erkenntnis 79 (S1):1-18.

Caso, R. (2014), “Assertion and Relative Truth,” Synthese 191: 1309-1325.

Davis, J. K. (2010), “An Alternative to Relativism,” Philosophical Topics 38 (2):17-37.

Dinges, A. (2017a): “Relativism and Assertion”, Australasian Journal of Philosophy 95(4): 730-740.

${ }^{16}$ See also Ross and Schroeder (2013, 69-70). 
--- (2017b): “Relativism, Disagreement and Testimony," Pacific Philosophical Quarterly 98: 497-519.

Dummett, M. (1959/1978), "Truth," in Dummett, Truth and Other Enigmas, Cambridge, Mass.: Harvard University Press, pp. 1-24.

Egan, A. (2007), "Epistemic modals, relativism and assertion," Philosophical Studies 133 (1): 1-22.

--- and D. Kindermann, "De Se Relativism", this volume.

Eriksson, J. and M. Tiozzo (2016), "Matters of ambiguity: faultless disagreement, relativism and realism," Philosophical Studies 173 (6): 1517-1536.

Evans, G. (1985), “Does Tense Logic Rest upon a Mistake?,” in Evans, Collected Papers, Oxford: Clarendon Press: 343-363.

Francén, R. (2010), “No Deep Disagreement for New Relativists," Philosophical Studies 151(1): 19-37.

Franzén, N. (2018), “Aesthetic Evaluation and First-Hand Experience," Australasian Journal of Philosophy 96(4): 669-682.

García-Carpintero, M. (2008), "Relativism, Vagueness and What Is Said," in GarcíaCarpintero and Kölbel (2008), 129-154.

García-Carpintero, M. and M. Kölbel (eds.)(2008), Relative Truth, Oxford: Oxford University Press.

--- and S. Torre (eds.) (2016), About Oneself, Oxford: Oxford University Press. 
Huvenes, T. (2012), "Varieties of Disagreement and Predicates of Taste," Australasian Journal of Philosophy 90(1): 167-181.

lacona, A. (2008), “Faultless or Disagreement,” In: García-Carpintero \& Kölbel (2008): 287-298.

Knobe, J. and S. Yalcin (2014), "Epistemic modals and context: Experimental data," Semantics and Pragmatics 7 (10): 1-21.

Khoo, J. and J. Knobe (2016), "Moral Disagreement and Moral Semantics", Noûs, 52:1 (2018): 109-143

Kölbel, M. (2003), “Faultless Disagreement," Proceedings of the Aristotelian Society 104: 53-73.

--- (2004), “Indexical Relativism vs Genuine Relativism," International Journal of Philosophical Studies 12 (2), 297-313.

--- (2009), "The evidence for relativism," Synthese 166, 375-395.

--- (2015), “Relativism 1: Representational Content," 10(1): 38-51.

Lewis, D. (1979), “Attitudes De Dicto and De Se," Philosophical Review 88: 513-43.

López de Sa, D. (2015), “Expressing disagreement: A presuppositional indexical contextualist relativist account," Erkenntnis 80: 153-165.

MacFarlane, John (2007), “Relativism and Disagreement," Philosophical Studies 132: 17-31.

--- (2011), “Epistemic modals are assessment-sensitive,"in Weatherson and Egan (Eds.), Epistemic Modality. Oxford: OUP: 144-178. 
--- (2014), Assessment Sensitivity: Relative Truth and Its Applications, Oxford: Oxford University Press.

--- (2016), "Replies to Raffman, Stanley, and Wright," Philosophy and

Phenomenological Research 92: 197-202.

Marques, T. (2014a): “Relative Correctness,” Philosophical Studies 167 (2): 361-373.

--- (2014b), “Doxastic Disagreement,” Erkenntnis 79 (S1): 121-142.

--- (2015), “Disagreeing in Context," Frontiers in Psychology 6: 1-12.

--- (2016), “Aesthetic Predicates: A Hybrid Dispositional Account," Inquiry 59 (6):723751.

--- (2018), “Retractions," Synthese 195 (8): 3335-3359.

--- (2019), "Hybrid Dispositionalism and the Law”. In Toh, Plunkett \& Shapiro (eds.), Dimensions of Normativity: New Essays on Metaethics and Jurisprudence. New York: OUP: $263-286$.

--- and M. García-Carpintero (2014), “Disagreement about taste: commonality presuppositions and coordination," Australasian Journal of Philosophy, 72 (4), 701-23.

Moruzzi, S. (2008), “Assertion, Belief and Disagreement," in García-Carpintero and Kölbel (2008), 207-224.

Palmira, M. (2015), "The Semantic Significance of Faultless Disagreement," Pacific Philosophical Quarterly 96 (3): 349-371. 
Parsons, J. (2013), "Presupposition, Disagreement, and Predicates of Taste," Proceedings of the Aristotelian Society 113: 163-173.

Plunkett, D. and T. Sundell (2013), “Disagreement and the Semantics of Normative and Evaluative Terms," Philosopher's Imprint 13: 1-37.

Ross, J. and M. Schroeder (2013), "Reversibility or Disagreement," Mind 122 (485): 4384.

Silk, A. (2016), Discourse Contextualism: A Framework for Contextualist Semantics and Pragmatics. Oxford: Oxford University Press.

Sarkissian, H., J. Park, D. Tien, J. Cole Wright, and J. Knobe (2011), "Folk Moral Relativism," Mind and Language 266 (4): 482-505.

Stevenson, C.L. (1944), Ethics and Language, New Haven: Yale University Press.

Sundell, T. (2011), “Disagreement about Taste,” Philosophical Studies 155, 2: 267-288.

Wright, C. (2016), "Assessment-Sensitivity: The Manifestation Challenge," Philosophy and Phenomenological Research 92: 189-196.

Zakkou, J. (2015), Tasty Contextualism. A Superiority Approach to the Phenomenon of Faultless Disagreement, Ph.D. Thesis, Humboldt University of Berlin.

--- (2019): “Denial and retraction: a challenge for theories of taste predicates," Synthese 196 (4): 1555-1573.

Zeman, D., "Faultless Disagreement," this volume. 